\title{
Programmed death-I/programmed death-I ligand axis as a therapeutic target in oncology: current insights
}

\author{
Kurt A Schalper' \\ Vyshak Alva Venur ${ }^{2}$ \\ Vamsidhar Velcheti ${ }^{2}$ \\ 'Department of Pathology, Yale \\ University, New Haven, CT, ${ }^{2}$ Solid \\ Tumor Oncology, Cleveland Clinic, \\ Cleveland, OH, USA
}

This article was published in the following Dove Press journal:

Journal of Receptor, Ligand and Channel Research

23 December 2014

Number of times this article has been viewed

\begin{abstract}
Over the past few years, the functional modulation of immune-checkpoint pathways using monoclonal antibodies has emerged as a promising anticancer therapeutic strategy. A key mechanism utilized by tumor cells to induce immune tolerance is upregulation of the programmed death-1 (PD-1) pathway. PD-1 is a negative coregulatory receptor on T-cells and antigen-presenting cells. The PD-1 ligand (PD-L1) is expressed by several tumor types, and appears to be dynamically regulated by the immune microenvironment. Several investigational agents targeting either PD-1 or PD-L1 are under clinical development and show durable antitumor activity across several tumor types. This review summarizes the conceptual basis, safety, and clinical activity of currently available PD-1 pathway therapeutic antibodies.

Keywords: immunotherapy, cancer, biomarkers, immune-checkpoint inhibitors, programmed death receptor
\end{abstract}

\section{Introduction}

The dynamic interactions between a tumor and the host immune system develop through a complex process referred to as "cancer immunoediting". This process allows the innate immune system to recognize and eliminate tumor cells, mainly through the cytotoxic effect of natural killer, CD4-positive, and CD8-positive T-cells, as well as interferon- $\gamma$ secretion. However, cancer cells can select mechanisms to adapt to and evade the immune response through generation of an immune-suppressive microenvironment, ultimately leading to cancer progression. The tumor microenvironment contains several suppressive mechanisms, including infiltration by specific inhibitory cells, eg, T regulatory cells and myeloid-derived suppressor cells, production of soluble immunosuppressive factors/cytokines, eg, interleukin (IL)-6, IL-10, vascular endothelial growth factor, and transforming growth factor- $\beta$, and activation of coinhibitory immune checkpoint pathways, eg, cytotoxic T-lymphocyte-associated protein (CTLA)-4 and programmed death-1 (PD-1)/PD-1 ligand (PD-L1).

The antitumor T-cell response is initiated through antigen recognition by the T-cell receptor and further modulated by costimulatory and coinhibitory signal checkpoints. Most of these checkpoints can act both at the antigen cell presentation level and in the transmission of signals from tumor to effector cells. It is increasingly recognized that upregulation of inhibitory checkpoints by cancer cells limits the effectiveness of immune surveillance. Such inhibitory pathways include: PD-1/PD-L1/PD-L2, CTLA-4/CD80/CD86, B lymphocyte and $\mathrm{T}$ lymphocyte attenuator/herpes virus entry mediator, lymphocyte-activation gene 3/major histocompatibility complex-II, T-cell immunoglobulin mucin-3/galectin 9, B7-H3, B7-H4, adenosine/A2A receptors, and indoleamine 2,3-dioxygenase.
Correspondence: Vamsidhar Velcheti Solid Tumor Oncology, Taussig Cancer Institute, Cleveland Clinic, 9500 Euclid Ave, R35 Cleveland, OH 44195, USA

Tel +l 2164448665

$\mathrm{Fax}+\mathrm{I} 2166362498$

Email velchev@ccf.org
Journal of Receptor, Ligand and Channel Research 2015:8 I-7

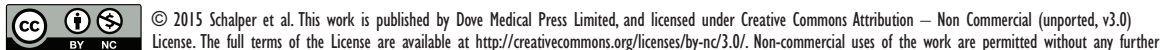
permission from Dove Medical Press limited, provided the work is properly attributed. Permisisions beyond the scope of the License are administered by Dove Medical Press Limited. Information on how to request permission may be found at http://www.dovepress. com//permisisions.php 
Several anticancer strategies involving immune modulatory approaches have been evaluated in recent decades, with varying degrees of success. Closer understanding of the immune brakes or inhibitory checkpoints used by tumor cells to evade the cytotoxic immune response has led to development of novel agents with unprecedented clinical potential. One such checkpoint pathway commonly upregulated in solid tumors is the PD-1/PD-L1 axis. ${ }^{1}$

\section{PD-I pathway and tumor immune escape}

PD-1 receptor, a member of the CD28 family, is a type 1 transmembrane protein with the extracellular segment containing a single immunoglobulin (Ig)-like variable domain and the intracellular part containing an immunoreceptor tyrosinebased inhibitory motif. ${ }^{2}$ PD-1 is expressed on activated T-cells, B lymphocytes, natural killer cells, dendritic cells, and activated monocytes. ${ }^{3,4}$ Interaction between PD-1 and its ligands PD-L1 and PD-L2 leads to T-cell exhaustion, inactivation, and apoptosis. Exhausted T lymphocytes lose the ability to produce proinflammatory cytokines including IL-2, tumor necrosis factor- $\alpha$, and interferon- $\gamma .,{ }^{4,5}$ In addition, binding of PD-1 to its ligands induces cell cycle arrest by increasing P15 and P27 expression. ${ }^{6}$ Expression of PD-L1 by diverse tissues mediates peripheral immune tolerance, and activation of the PD-1/PD-L1 axis limits the tissue damage after a sustained immune/inflammatory response. PD-1-expressing tumorinfiltrating lymphocytes are associated with an impaired antitumor effect and upregulation of PD-1, and PD-L1 is associated with outcome in several tumor types. ${ }^{7-10}$

To date, two PD-1 ligands from the B7 family have been characterized, ie, PD-L1 (B7-H1, CD274) and PD-L2 (B7-DC, CD273). PD-L1 is constitutively expressed in immunologically privileged sites like the placenta, retina, and tonsils, ${ }^{11-13}$ as well as in macrophages and dendritic cells. ${ }^{4}$ PD-L1 is upregulated in various tumors, including melanoma, high-grade glioma, and non-small cell lung cancer (NSCLC), as well as ovarian, breast, squamous cell head and neck (SCHN), and cervical carcinoma. ${ }^{14,15}$

Some investigators have reported that tumor PD-L1 expression is associated with an adverse outcome, ${ }^{16,17}$ while other studies have found a favorable outcome with increased PD-L1 expression. ${ }^{15,18-21}$ The performance of most commercially available antibodies against PD-L1 is unknown, and the data suggest limitations in the specificity and reproducibility of some assays that might explain the dissimilar association with outcome and limited predictive value for anti-PD-1/PD-L1 therapies. ${ }^{21,22}$ In general, tumor PD-L1 positivity has been associated with a higher likelihood of response to therapies (see below). However, clinical trials have measured tumor tissue PD-L1 using automated immunohistochemistry with different antibodies including Dako clone 28-8 (nivolumab, Bristol-Myers Squibb, New York, NY, USA), Dako clone 22C3 (pembrolizumab, Merck, Whitehouse Station, TX, USA), Spring Biosciences clone SP142 (MPDL3280A, Genentech, South San Francisco, CA, USA), and Spring Biosciences clone SP262 (MEDI4736, AstraZeneca, London, UK). To date, the properties and concordance between these immunohistochemistry antibodies has not been reported, and only clone SP142 has become commercially available. In addition, the scoring system used in clinical trials and the definition of PD-L1 positivity is different across studies. While some groups consider only the membranous staining of tumor cells to indicate PD-L1 positivity; others score the PD-L1 signal only in tumor-infiltrating lymphocytes. The percentages of positive cells required to consider the case as positive or negative are also dissimilar. Future studies will be required to clarify the optimal immunohistochemistry assay to predict clinical benefit.

Recent studies using validated antibodies in diverse tumor types, including melanoma, lung, SCHN, and breast carcinoma, ${ }^{15,20-22}$ suggest that PD-L1 expression may actually be an indication of an ongoing interferon- $\gamma$-mediated antitumor response resulting in adaptive resistance of the tumor by increased PD-L1 expression. These findings are supported by results obtained using antibody-independent assays to measure in situ PD-L1 mRNA transcripts in cancer tissues and by studies showing a positive association between PD-L1 expression and the presence of immune infiltrates. ${ }^{20,21,23}$ It has been convincingly demonstrated that PD-L1 protein production is upregulated in certain cells on exposure to interferon- $\gamma^{23}$ In addition, PD-L1 protein expression is regulated by signal transducer and activator of transcription 3 and c-Jun, ${ }^{24}$ but their expression on tumor cells is controlled by posttranslational mechanisms in the tumor microenvironment. ${ }^{14}$ Interaction between PD-1 on activated T-cells and PD-L1 on the surface of tumor cells leads to downmodulation of the T-cell receptor via upregulation of Casitas B-lymphoma (Cbl)-b E3 ubiquitin ligase ${ }^{25}$ (Figure 1). PD-L2 expression has been found in macrophages, dendritic cells, and some neoplasms, but its role in the genesis and progression of solid tumors remains largely unexplored. Of note, PD-1 has two to six times more affinity for PD-L2 than for PD-L1, ${ }^{26}$ but since PD-L2 is expected not to be commonly present in tumor cells, it has been considered as a less critical mechanism of tumor immune modulation. ${ }^{5}$ Further studies screening for PD-L2 expression in various tumors using standardized assays will 


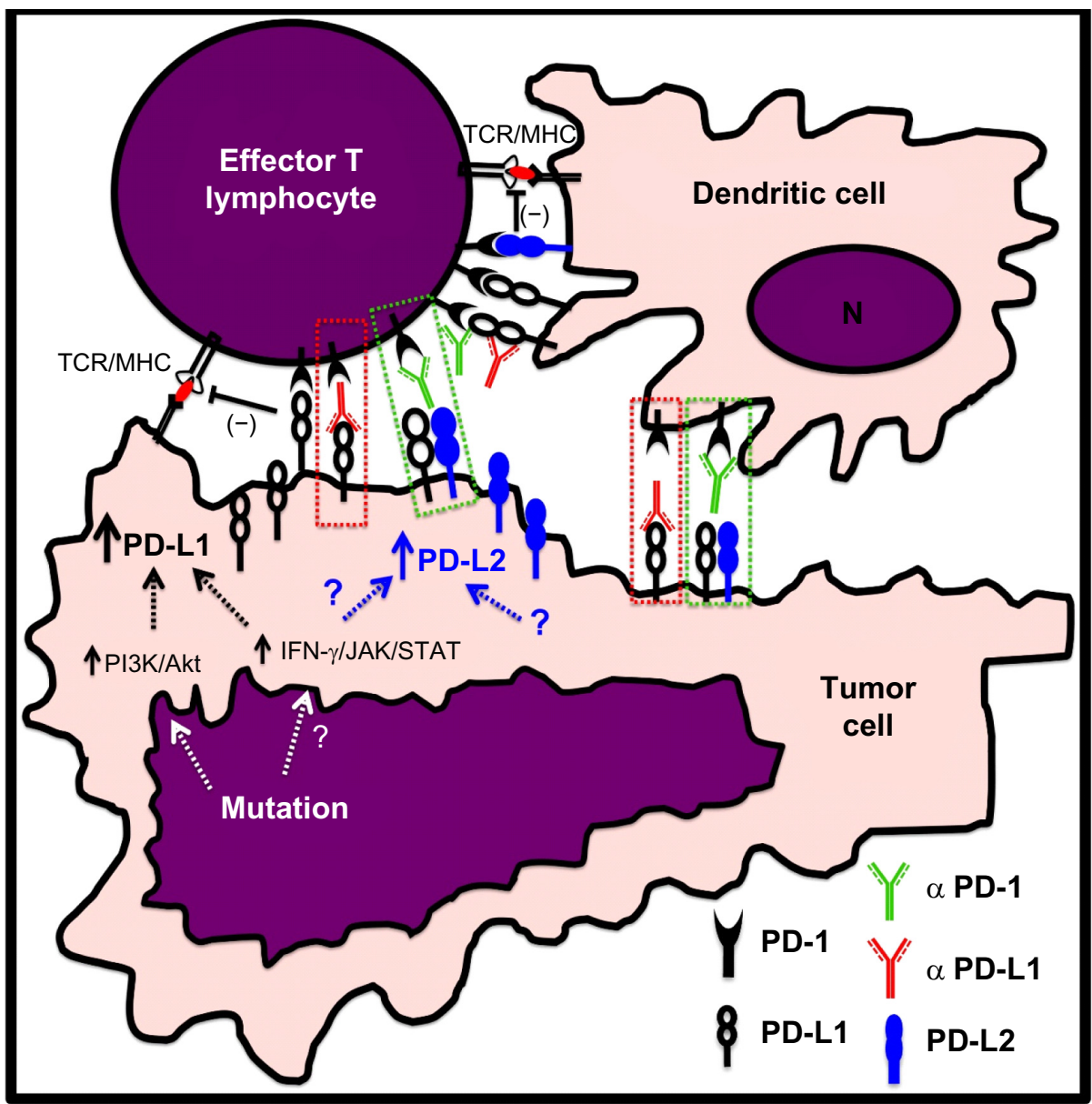

Figure I Modulation of the immune inhibitory PD-I/PD-LI axis for anticancer treatment using monoclonal antibodies.

Notes: The diagram indicates the predicted functional interaction between tumor cells, T lymphocytes, and dendritic cells in the tumor microenvironment and highlights the two major mechanisms for PD-I/PD-LI pathway blockade using monoclonal antibodies against PD-I (red Ig) and PD-LI (green Ig). After antigen recognition and activation of T lymphocytes through a TCR/MHC peptide-based interaction, cytotoxic cells become inactive by negative costimulatory signals from the PD-I/PD-LI axis. Signaling from PI3K and interferon pathways can upregulate PD-LI in tumor cells. The role and functional modulation of PD-L2 in the antitumor immune evasion and pharmacological blockade of the PD-I/PD-LI axis is not well understood.

Abbreviations: TCR, T-cell receptor; MHC, major histocompatibility complex; PD-I, programmed death-I; PD-LI, programmed death-I ligand; PD-L2, programmed death-2 ligand; PI3K, phosphatidylinositol-4 5-bisphosphate 3-kinase; Ig, immunoglobulin; IFN- $\gamma$, interferon gamma; JAK, Janus kinase; STAT, signal transducer and activator of transcription.

be required to clarify this. The precise contribution of PD-L2 in the effect of PD-1 receptor blockade using monoclonal antibodies is yet to be determined.

Therapeutic approaches blocking the PD-1 pathway demonstrate prominent antitumor responses in preclinical models by augmenting effector T-cell function. ${ }^{27-30}$ Several studies demonstrate a synergistic effect of combination of PD-1/ PD-L1 blockade with other immunotherapy strategies and chemotherapy. ${ }^{29,31,32}$ In vitro studies have shown that blockade of PD-1 signaling on T-cells not only enhances T-cell effector function, but also increases homing to the tumor microenvironment, T-cell proliferation, and cytotoxicity. In general, the PD-1/PD-L1 pathway plays a pivotal role in the regulation of T-cell proliferation in response to persisting antigens. In addition, PD-1/PD-L1 upregulation leads to impaired dendritic cells and depletion of activated memory B-cells. ${ }^{33}$

\section{PD-I pathway-targeting agents under clinical development}

There are several therapeutic antibodies targeting PD-1 or PD-L1 in clinical development (Table 1). Targeting PD-1 and PD-L1 has lasting antitumor activity in diverse tumor types and some of these compounds are in advanced clinical development. These agents have varying clinical activity and toxicity profiles (Table 2).

\section{PD-I inhibitors}

\section{Nivolumab}

Nivolumab (BMS-936558, MDX1106, ONO4538) is a fully human IgG4-blocking monoclonal antibody against PD-1. Since blockade of the axis occurs at the receptor level, nivolumab is expected to inhibit both PD-L1-mediated and PD-L2-mediated signaling (Figure 1). Its half-life is 
Table I General characteristics of therapeutic PD-I and PD-LI monoclonal antibodies

\begin{tabular}{llll}
\hline Drug & Company & Isotype & Development stage \\
\hline $\begin{array}{l}\text { PD-I monoclonal antibodies } \\
\text { Nivolumab, BMS936558, MDXII06 }\end{array}$ & Bristol-Myers Squibb & Fully human IgG4 & Phase III \\
$\begin{array}{l}\text { Pidilizumab, CT0II } \\
\text { Pembrolizumab, MK3475 }\end{array}$ & Cure Tech & Humanized IgGI & Phase II \\
PD-LI monoclonal antibodies & Merck & Humanized IgG4 & Phase III \\
BMS936559, MDX-II05 & & & \\
MEDI4736 & Bristol-Myers Squibb & Fully human IgG4 & Phase II \\
MPDL3280A, RG7446 & Medlmmune & Human IgGI & Phase III \\
\hline
\end{tabular}

Abbreviations: Ig, immunoglobulin; PD-I, programmed death-I; PD-LI, programmed death-I ligand.

dose-dependent, ranging from 12 to 20 hours. The maximum tolerated dose was not achieved in the Phase I studies using doses of $0.3,1,3$, and $10 \mathrm{mg} / \mathrm{kg}$. The most common adverse events associated with nivolumab are fatigue (24\%), rash $(12 \%)$, pruritus $(10 \%)$, diarrhea $(11 \%)$, decreased appetite $(8 \%)$, and nausea $(8 \%)$. Immune-related adverse events, including colitis, thyroiditis, hepatitis, and pneumonitis, were observed in $18 \%$ of patients. ${ }^{34,35}$ Adverse events, including immune-related adverse events, were similar across dosing schedules and tumor types, and grade $3 / 4$ toxicities were observed in $15 \%-20 \%$ of patients. ${ }^{34,36}$ In an ongoing Phase I (CA209003) trial of nivolumab monotherapy with multiple expansion cohorts, durable responses were noted in patients with refractory advanced solid tumors, including NSCLC, renal cell carcinoma, and melanoma. ${ }^{34}$ An objective response rate (ORR) was seen in 22/129 (17\%) patients with NSCLC, in 33/107 (31\%) subjects with advanced melanoma, and in $10 / 34(29 \%)$ patients with renal cell carcinoma. Over $50 \%$ of the patients with objective responses had a durable benefit for more than one year, and $70 \%$ retained the response (for longer than 4 months) even with discontinuation of treatment after 2 years. ${ }^{34}$ In the early Phase I studies of nivolumab monotherapy, patients with PD-L1 protein expression had a 40\%-70\% ORR compared with $<10 \%$ in patients lacking PD-L1. ${ }^{37}$ In a Phase I trial of nivolumab in combination with platinum doublet therapy in NSCLC, grade 3/4 adverse events were reported in $45 \%$ of patients and were comparable with the platinum doublet alone. Grade 3/4 immune-related adverse events requiring discontinuation of nivolumab were most commonly pneumonitis and acute nephritis, and occurred in $15 \%$ of patients. The ORR for nivolumab in combination with the platinum doublet was in the range of $33 \%-47 \%$ across treatment arms..$^{38}$ Interim analysis of the combination of nivolumab and erlotinib in epidermal growth factor receptor-mutant NSCLC with acquired resistance to erlotinib showed an encouraging ORR of $19 \%$. This combination had a low frequency (24\%) of grade 3/4 adverse events. ${ }^{39}$ In advanced solid tumors (NSCLC, melanoma, and renal cell

Table 2 Clinical activity and toxicity profile of PD-I and PD-LI inhibitors

\begin{tabular}{|c|c|c|c|}
\hline Drug & Efficacy (ORR) & Toxicity grade $\geq 3$ & Pneumonitis \\
\hline \multicolumn{4}{|l|}{ PD-I inhibitors } \\
\hline Nivolumab, BMS936558, & NSCLC, I8\% (with platinum doublet chemotherapy ORR 33\%) & I4\% with monotherapy, $49 \%$ & $3 \%$ \\
\hline \multirow[t]{2}{*}{ MDXII06 } & Melanoma, 28\% (with ipilimumab ORR 40\%) & with platinum doublet and $53 \%$ & \\
\hline & Renal cell carcinoma $27 \%$ & in combination with ipilimumab & \\
\hline \multirow[t]{3}{*}{ Pidilizumab, CTOII } & Melanoma, $6 \%$ & $0 \%$ & $0 \%$ \\
\hline & Refractory DLBCL, 5 I\% & & \\
\hline & Refractory follicular lymphoma, $66 \%$ (in combination with rituximab) & & \\
\hline \multirow[t]{2}{*}{ Pembrolizumab, MK3475 } & NSCLC, $24 \%$ & $13 \%$ & $4 \%$ \\
\hline & Melanoma, $38 \%$ & & \\
\hline \multicolumn{4}{|l|}{ PD-LI inhibitors } \\
\hline BMS936559 & NSCLC & $9 \%$ & $0 \%$ \\
\hline \multirow[t]{2}{*}{ MDX-II 05} & Melanoma & & \\
\hline & Renal cell carcinoma & & \\
\hline \multirow[t]{2}{*}{ MEDI4736 } & NSCLC, $13 \%$ & $7 \%$ & $0 \%$ \\
\hline & $\mathrm{SCHN}, \mathrm{I} \%$ & & \\
\hline \multirow[t]{4}{*}{ MPDL3280A RG7446 } & NSCLC, $22 \%$ & $13 \%$ & $0 \%$ \\
\hline & Melanoma, $29 \%$ & & \\
\hline & Renal cell carcinoma, I3\% & & \\
\hline & Bladder cancer, $43 \%$ (in PD-LI+) & & \\
\hline
\end{tabular}

Abbreviations: DLBCL, diffuse large B-cell lymphoma; NSCLC, non-small cell lung cancer; SCHN, squamous cell head and neck; PD-I, programmed death-I; PD-LI, programmed death-I ligand; ORR, objective response rate. 
carcinoma), combination of nivolumab with ipilimumab, a CTLA-4 inhibitor, was feasible and provided a durable ORR regardless of PD-L1 expression. ${ }^{40,41}$ Several ongoing Phase II/III trials are underway using nivolumab as a single agent and in combination with chemotherapy or additional immunotherapy in various tumors. ${ }^{41-44}$

\section{Pembrolizumab}

Pembrolizumab (previously known as lambrolizumab or MK-3475) is a humanized monoclonal antibody (IgG4-kappa isotype) targeting the $\mathrm{PD}-1$ receptor. It lacks antibody-dependent cell cytotoxicity. The half-life of the drug is around 2-3 weeks. The maximum tolerated dose was not reached in the Phase I studies at 1,3 and $10 \mathrm{mg} / \mathrm{kg}$ dosing. ${ }^{45}$ A Phase I study of MK-3475 (KEYNOTE 001 trial) was conducted in advanced refractory solid tumors including NSCLC and melanoma. Adverse events of any grade were reported in $79 \%$ of patients, $13 \%$ had grade $3-4$ adverse events related to the drug. Of note, $4 \%$ of patients had drug-related pneumonitis. Hypothyroidism was reported in $8 \%$ of the patients and diarrhea in $20 \% .{ }^{46}$ In the reported Phase I studies of advanced malignancies, the ORR was approximately $20 \%$ in NSCLC and 50\% in melanoma. ${ }^{47-50}$ In patients with $\mathrm{PD}-\mathrm{L} 1$ expression, the responses were significantly higher, at $\sim 50 \%$ for NSCLC and melanoma and only $\sim 10 \%$ in subjects with PD-L1 negative tumors. In another Phase I trial in recurrent/metastatic SCHN, 11/56 of patients had responses (ORR 19.6\%) regardless of human papilloma virus status. ${ }^{51}$ Pembrolizumab is currently being investigated in combination with different chemotherapy and immunotherapy regimens in various tumors.

\section{Pidilizumab}

Pidilizumab (CT-011) is a humanized IgG1k monoclonal antibody against PD-1. A Phase I study was conducted in 17 patients with hematologic malignancies, of whom eight had acute myeloid leukemia, three had non-Hodgkin's lymphoma, three had chronic lymphocytic lymphoma, one had Hodgkin's lymphoma, one had multiple myeloma, and one had myelodysplastic syndrome. ${ }^{52}$ The dose ranges evaluated were between 0.2 and $6 \mathrm{mg} / \mathrm{kg}$. The maximal tolerated dose was not reached. The half-life was between 9 and 17 days, with linear exposure across doses. A clinical response was observed in one third of the patients. One patient with non-Hodgkin's lymphoma had a complete response and four patients achieved stable disease (two with chronic lymphocytic lymphoma, one with Hodgkin's lymphoma, and one with multiple myeloma).$^{53}$ A Phase II study of pidilizumab in 72 patients with diffuse large B-cell lymphoma and measurable disease after an autologous hematopoietic stem cell transplant demonstrated a significant ORR of $51 \%{ }^{54}$ Pidilizumab is also being investigated in combination with rituximab in relapsed follicular lymphoma, and was well tolerated with no grade 3-4 toxicities and clinical responses in 19/29 subjects (ORR 66\%). ${ }^{55}$ In a Phase II trial in advanced melanoma, the ORR was $6 \%$ with a one-year survival of $64 \% .^{56}$

\section{PD-LI inhibitors MPDL3280A}

MPDL3280A is a fully human monoclonal antibody with an engineered Fc portion targeting PD-L1. Therefore, PD-L2 mediated signaling is not expected to be affected by this agent (Figure 1). This change in the Fc portion is designed to avoid antibody-dependent cell cytotoxicity, thus sparing the bystander immune cells expressing PD-L1. In preliminary Phase I results for 171 patients with refractory and metastatic solid tumors, no maximal tolerated dose was observed. No treatment-related deaths were seen. Grade 3/4 treatment-related adverse events were noted in $13 \%$ of patients and only $2 \%$ had immune-related grade $3 / 4$ adverse events. No grade $3 / 4$ pneumonitis was seen. A total of 140 patients were evaluable for efficacy, with an ORR of $21 \%$ in all patients $(22 \%$ in NSCLC, $29 \%$ in melanoma, and $13 \%$ in renal cell carcinoma), and the responses were durable. The response rates were $36 \%$ in patients with $\mathrm{PD}-\mathrm{L} 1$ positive tumors and 13\% in PD-L1 negative cases. ${ }^{57,58}$ In an expansion cohort of patients with metastatic and refractory PD-L1 positive bladder cancer, 13/30 patients had responses (ORR 43\%). ${ }^{59}$ Several ongoing trials are investigating the role of MPDL3280A in solid tumors. ${ }^{60}$

\section{MEDI4736}

MEDI4736 is an engineered human IgG1 antibody against PD-L1. It has high affinity and selectivity for PD-L1. Preliminary data from a multi-arm Phase I expansion trial in advanced solid tumors showed indications of clinical activity in various tumors. ${ }^{61,62}$ This study included NSCLC, SCHN, melanoma, renal cell carcinoma, and colorectal cancer patients. The drug was well tolerated, with $7 \%$ treatment-related grade $3 / 4$ adverse events not requiring therapy discontinuation. Early responses were noted, and a dose of $10 \mathrm{mg} / \mathrm{kg}$ every 2 weeks for 12 months was selected for further development of the drug as monotherapy and in combination with other treatments.

\section{BMS-936559}

BMS-936559 (MDX-1105) is a humanized IgG4 monoclonal antibody against PD-L1. In a Phase I study of 207 patients with advanced refractory solid tumors using a dose range of $0.3-10 \mathrm{mg} / \mathrm{kg}$, no maximum dose was defined. ${ }^{63}$ The estimated half-life was in the range of 10-15 days. Clinical responses were seen in 9/52 (17\%) in melanoma and 
5/49 (10\%) in NSCLC patients. Grade 3-4 treatment-related adverse events were noted in $9 \%$ of the patients. There are currently no ongoing trials with this agent.

\section{Final remarks and conclusion}

After many years of immunotherapy showing only limited results in anticancer treatment, targeting of the PD-1/PD-L1 axis using therapeutic monoclonal antibodies has emerged as an effective strategy. Blockade of PD-1 or PD-L1 induces prominent and lasting clinical responses, with acceptable toxicity in 15\%-30\% of patients with advanced (and heavily pretreated) tumors. Although further work is required to understand the intimate mechanistic aspects and optimal treatment modalities, a myriad of antibodies are available, many with ongoing clinical trials. Modulation of additional costimulatory and coinhibitory checkpoints (together with PD-1/PD-L1 blockade or alone) is also ongoing and has the potential to expand the current repertoire of immunotherapy options for treating cancer in the near future.

\section{Disclosure}

The authors report no conflicts of interest in this work.

\section{References}

1. Schreiber RD, Old LJ, Smyth MJ. Cancer immunoediting: integrating immunity's roles in cancer suppression and promotion. Science. 2011;331(6024):1565-1570.

2. Freeman GJ, Long AJ, Iwai Y, et al. Engagement of the PD-1 immunoinhibitory receptor by a novel B7 family member leads to negative regulation of lymphocyte activation. J Exp Med. 2000;192(7): $1027-1034$.

3. Agata Y, Kawasaki A, Nishimura H, et al. Expression of the PD-1 antigen on the surface of stimulated mouse $\mathrm{T}$ and $\mathrm{B}$ lymphocytes. Int Immunol. 1996;8(5):765-772.

4. Keir ME, Butte MJ, Freeman GJ, Sharpe AH. PD-1 and its ligands in tolerance and immunity. Anпu Rev Immunol. 2008;26:677-704.

5. Flies DB, Sandler BJ, Sznol M, Chen L. Blockade of the B7-H1/PD-1 pathway for cancer immunotherapy. Yale J Biol Med. 2011;84(4): 409-421.

6. Patsoukis N, Brown J, Petkova V, Liu F, Li L, Boussiotis VA. Selective effects of PD-1 on Akt and Ras pathways regulate molecular components of the cell cycle and inhibit T cell proliferation. Sci Signal. 2012;5(230):ra46.

7. Ahmadzadeh M, Johnson LA, Heemskerk B, et al. Tumor antigenspecific CD8 T cells infiltrating the tumor express high levels of PD-1 and are functionally impaired. Blood. 2009;114(8):1537-1544.

8. Zhang Y, Huang S, Gong D, Qin Y, Shen Q. Programmed death-1 upregulation is correlated with dysfunction of tumor-infiltrating CD8+ T lymphocytes in human non-small cell lung cancer. Cell Mol Immunol. 2010;7(5):389-395.

9. Thompson RH, Dong H, Lohse CM, et al. PD-1 is expressed by tumorinfiltrating immune cells and is associated with poor outcome for patients with renal cell carcinoma. Clin Cancer Res. 2007;13(6):1757-1761.

10. Shi F, Shi M, Zeng Z, et al. PD-1 and PD-L1 upregulation promotes CD8(+) T-cell apoptosis and postoperative recurrence in hepatocellular carcinoma patients. Int J Cancer. 2011;128(4):887-896.

11. Nagamatsu T, Schust DJ, Sugimoto J, Barrier BF. Human decidual stromal cells suppress cytokine secretion by allogenic CD4+ T cells via PD-1 ligand interactions. Hum Reprod. 2009;24(12):3160-3171.
12. Jacobs JF, Idema AJ, Bol KF, et al. Regulatory T cells and the PD-L1/ $\mathrm{PD}-1$ pathway mediate immune suppression in malignant human brain tumors. Neuro Oncol. 2009;11(4):394-402.

13. Iwai Y, Okazaki T, Nishimura H, Kawasaki A, Yagita H, Honjo T. Microanatomical localization of PD-1 in human tonsils. Immunol Lett. 2002;83(3):215-220.

14. Hirano F, Kaneko K, Tamura H, et al. Blockade of B7-H1 and PD-1 by monoclonal antibodies potentiates cancer therapeutic immunity. Cancer Res. 2005;65(3):1089-1096.

15. Vasilakopoulou M, Velcheti V, Rampias T, et al. Effect of PDL-1 expression on prognosis in head and neck squamous cell carcinoma. ASCO Meeting Abstracts. 2013;31(Suppl 15):6012.

16. Wu C, Zhu Y, Jiang J, Zhao J, Zhang XG, Xu N. Immunohistochemical localization of programmed death-1 ligand-1 (PD-L1) in gastric carcinoma and its clinical significance. Acta Histochem. 2006;108(1):19-24.

17. Mu CY, Huang JA, Chen Y, Chen C, Zhang XG. High expression of $\mathrm{PD}-\mathrm{L} 1$ in lung cancer may contribute to poor prognosis and tumor cells immune escape through suppressing tumor infiltrating dendritic cells maturation. Med Oncol. 2011;28(3):682-688.

18. Hino R, Kabashima K, Kato Y, et al. Tumor cell expression of programmed cell death-1 ligand 1 is a prognostic factor for malignant melanoma. Cancer. 2010;116(7):1757-1766.

19. Liu Y, Carlsson R, Ambjorn M, et al. PD-L1 expression by neurons nearby tumors indicates better prognosis in glioblastoma patients. J Neurosci. 2013;33(35):14231-14245.

20. Schalper KA, Velcheti V, Carvajal D, et al. In situ tumor PD-L1 mRNA expression is associated with increased TILs and better outcome in breast carcinomas. Clin Cancer Res. 2014;20(10):2773-2782.

21. Velcheti V, Schalper KA, Carvajal DE, et al. Programmed death ligand-1 expression in non-small cell lung cancer. Lab Invest. 2014; 94(1):107-116.

22. Taube JM, Klein AP, Brahmer JR, et al. Association of PD-1, PD-1 ligands, and other features of the tumor immune microenvironment with response to anti-PD-1 therapy. Clin Cancer Res. April 8, 2014. [Epub ahead of print.]

23. Dong H, Strome SE, Salomao DR, et al. Tumor-associated B7-H1 promotes T-cell apoptosis: a potential mechanism of immune evasion. Nat Med. 2002;8(8):793-800.

24. Jiang X, Zhou J, Giobbie-Hurder A, Wargo J, Hodi FS. The activation of MAPK in melanoma cells resistant to BRAF inhibition promotes PD-L1 expression that is reversible by MEK and PI3K inhibition. Clin Cancer Res. 2013;19(3):598-609.

25. Karwacz K, Bricogne C, MacDonald D, et al. PD-L1 co-stimulation contributes to ligand-induced $\mathrm{T}$ cell receptor down-modulation on $\mathrm{CD} 8+$ T cells. EMBO Mol Med. 2011;3(10):581-592.

26. Youngnak P, Kozono Y, Kozono H, et al. Differential binding properties of B7-H1 and B7-DC to programmed death-1. Biochem Biophys Res Commun. 2003;307(3):672-677.

27. Wong RM, Scotland RR, Lau RL, et al. Programmed death-1 blockade enhances expansion and functional capacity of human melanoma antigen-specific CTLs. Int Immunol. 2007;19(10):1223-1234.

28. Zhou Q, Xiao H, Liu Y, et al. Blockade of programmed death-1 pathway rescues the effector function of tumor-infiltrating $\mathrm{T}$ cells and enhances the antitumor efficacy of lentivector immunization. J Immunol. 2010;185(9):5082-5092.

29. Nomi T, Sho M, Akahori T, et al. Clinical significance and therapeutic potential of the programmed death-1 ligand/programmed death-1 pathway in human pancreatic cancer. Clin Cancer Res. 2007;13(7):2151-2157.

30. Iwai Y, Terawaki S, Honjo T. PD-1 blockade inhibits hematogenous spread of poorly immunogenic tumor cells by enhanced recruitment of effector T cells. Int Immunol. 2005;17(2):133-144.

31. Curran MA, Montalvo W, Yagita H, Allison JP. PD-1 and CTLA-4 combination blockade expands infiltrating $\mathrm{T}$ cells and reduces regulatory $\mathrm{T}$ and myeloid cells within B16 melanoma tumors. Proc Natl Acad Sci U SA. 2010;107(9):4275-4280.

32. Zeng J, See AP, Phallen J, et al. Anti-PD-1 blockade and stereotactic radiation produce long-term survival in mice with intracranial gliomas. Int J Radiat Oncol Biol Phys. 2013;86(2):343-349. 
33. Wang X, Zhang Z, Zhang S, et al. B7-H1 up-regulation impairs myeloid DC and correlates with disease progression in chronic HIV-1 infection. Eur J Immunol. 2008;38(11):3226-3236.

34. Topalian SL, Sznol M, Brahmer JR, et al. Nivolumab (anti-PD-1; BMS-936558; ONO-4538) in patients with advanced solid tumors: survival and long-term safety in a phase I trial. ASCO Meeting Abstracts. 2013;31(Suppl 15):3002.

35. Brahmer JR, Drake CG, Wollner I, et al. Phase I study of single-agent anti-programmed death-1 (MDX-1106) in refractory solid tumors: safety, clinical activity, pharmacodynamics, and immunologic correlates. J Clin Oncol. 2010;28(19):3167-3175.

36. Topalian SL, Hodi FS, Brahmer JR, et al. Safety, activity, and immune correlates of anti-PD-1 antibody in cancer. NEngl J Med. 2012;366(26): 2443-2454.

37. Gettinger SN, Shepherd FA, Antonia SJ, et al. First-line nivolumab (antiPD-1; BMS-936558, ONO-4538) monotherapy in advanced NSCLC: safety, efficacy, and correlation of outcomes with PD-L1 status. ASCO Meeting Abstracts. 2014;32(Suppl 15):8024.

38. Antonia SJ, Brahmer JR, Gettinger SN, et al. Nivolumab (anti-PD-1; BMS-936558, ONO-4538) in combination with platinum-based doublet chemotherapy (PT-DC) in advanced non-small cell lung cancer (NSCLC). ASCO Meeting Abstracts. 2014;32(Suppl 15):8113.

39. Rizvi NA, Chow LQM, Borghaei H, et al. Safety and response with nivolumab (anti-PD-1; BMS-936558, ONO-4538) plus erlotinib in patients (pts) with epidermal growth factor receptor mutant (EGFR MT) advanced NSCLC. ASCO Meeting Abstracts. 2014;32(Suppl 15):8022.

40. Wolchok JD, Kluger H, Callahan MK, et al. Nivolumab plus ipilimumab in advanced melanoma. $N$ Engl J Med. 2013;369(2):122-133.

41. Antonia SJ, Gettinger SN, Chow LQM, et al. Nivolumab (anti-PD-1; BMS-936558, ONO-4538) and ipilimumab in first-line NSCLC: interim phase I results. ASCO Meeting Abstracts. 2014;32(Suppl 15):8023.

42. Sznol M, Kluger HM, Callahan MK, et al. Survival, response duration, and activity by BRAF mutation (MT) status of nivolumab (NIVO, antiPD-1, BMS-936558, ONO-4538) and ipilimumab (IPI) concurrent therapy in advanced melanoma (MEL). ASCO Meeting Abstracts. 2014;32(Suppl 15):LBA9003.

43. Hamanishi J, Mandai M, Ikeda T, et al. Efficacy and safety of antiPD-1 antibody (Nivolumab: BMS-936558, ONO-4538) in patients with platinum-resistant ovarian cancer. ASCO Meeting Abstracts. 2014;32(Suppl 15):5511.

44. Sampson JH, Vlahovic G, Desjardins A, et al. Randomized phase IIb study of nivolumab (anti-PD-1; BMS-936558, ONO-4538) alone or in combination with ipilimumab versus bevacizumab in patients (pts) with recurrent glioblastoma (GBM). ASCO Meeting Abstracts. 2014;32(Suppl 15):TPS2101.

45. Patnaik A, Kang SP, Tolcher AW, et al. Phase I study of MK-3475 (antiPD-1 monoclonal antibody) in patients with advanced solid tumors. J Clin Oncol. 2012;30 Suppl:2512.

46. Garon EB, Balmanoukian A, Hamid O, et al. Abstract A20: MK-3475 monotherapy for previously treated non-small cell lung cancer (NSCLC): preliminary safety and clinical activity. Clin Cancer Res. 2014;20(Supp1 2):A20.

47. Garon EB, Leighl NB, Rizvi NA, et al. Safety and clinical activity of MK-3475 in previously treated patients (pts) with non-small cell lung cancer (NSCLC). ASCO Meeting Abstracts. 2014;32(Suppl 15):8020.
48. Rizvi NA, Garon EB, Patnaik A, et al. Safety and clinical activity of MK-3475 as initial therapy in patients with advanced non-small cell lung cancer (NSCLC). ASCO Meeting Abstracts. 2014;32(Suppl 15):8007.

49. Hamid O, Robert C, Daud A, et al. Safety and tumor responses with lambrolizumab (anti-PD-1) in melanoma. N Engl J Med. 2013;369(2): 134-144.

50. Ribas A, Hodi FS, Kefford R, et al. Efficacy and safety of the anti-PD-1 monoclonal antibody MK-3475 in 411 patients (pts) with melanoma (MEL). ASCO Meeting Abstracts. 2014;32(Suppl 18):LBA9000.

51. Seiwert TY, Burtness B, Weiss J, et al. A phase Ib study of MK-3475 in patients with human papillomavirus (HPV)-associated and nonHPV-associated head and neck $(\mathrm{H} / \mathrm{N})$ cancer. ASCO Meeting Abstracts. 2014;32(Suppl 15):6011.

52. Berger R, Rotem-Yehudar R, Slama G, et al. Phase I safety and pharmacokinetic study of CT-011, a humanized antibody interacting with PD-1, in patients with advanced hematologic malignancies. Clin Cancer Res. 2008;14(10):3044-3051.

53. Hamid O, Carvajal RD. Anti-programmed death-1 and anti-programmed death-ligand 1 antibodies in cancer therapy. Expert Opin Biol Ther. 2013;13(6):847-861.

54. Armand P, Nagler A, Weller EA, et al. Disabling immune tolerance by programmed death-1 blockade with pidilizumab after autologous hematopoietic stem-cell transplantation for diffuse large B-cell lymphoma: results of an international phase II trial. J Clin Oncol. 2013;31(33):4199-4206.

55. Westin JR, Chu F, Zhang M, et al. Safety and activity of PD1 blockade by pidilizumab in combination with rituximab in patients with relapsed follicular lymphoma: a single group, open-label, phase 2 trial. Lancet Oncol. 2014;15(1):69-77.

56. Atkins MB, Kudchadkar RR, Sznol M, et al. Phase 2, multicenter, safety and efficacy study of pidilizumab in patients with metastatic melanoma. ASCO Meeting Abstracts. 2014;32(Suppl 15):9001.

57. Herbst RS, Gordon MS, Fine GD, et al. A study of MPDL3280A, an engineered PD-L1 antibody in patients with locally advanced or metastatic tumors. ASCO Meeting Abstracts. 2013;31(Suppl 15):3000.

58. Spigel DR, Gettinger SN, Horn L, et al. Clinical activity, safety, and biomarkers of MPDL3280A, an engineered PD-L1 antibody in patients with locally advanced or metastatic non-small cell lung cancer (NSCLC). ASCO Meeting Abstracts. 2013;31(Suppl 15):8008.

59. Powles T, Vogelzang NJ, Fine GD, et al. Inhibition of PD-L1 by MPDL3280A and clinical activity in pts with metastatic urothelial bladder cancer (UBC). ASCO Meeting Abstracts. 2014;32(Suppl 15):5011.

60. Rizvi NA, Chow LQM, Dirix LY, et al. Clinical trials of MPDL3280A (anti-PDL1) in patients (pts) with non-small cell lung cancer (NSCLC). ASCO Meeting Abstracts. 2014;32(Suppl 15):TPS8123.

61. Lutzky J, Antonia SJ, Blake-Haskins A, et al. A phase 1 study of MEDI4736, an anti-PD-L1 antibody, in patients with advanced solid tumors. ASCO Meeting Abstracts. 2014;32(Suppl 15):3001.

62. Segal NH, Antonia SJ, Brahmer JR, et al. Preliminary data from a multi-arm expansion study of MEDI4736, an anti-PD-L1 antibody. ASCO Meeting Abstracts. 2014;32(Suppl 15):3002.

63. Brahmer JR, Tykodi SS, Chow LQ, et al. Safety and activity of antiPD-L1 antibody in patients with advanced cancer. $N$ Engl J Med. 2012;366(26):2455-2465.
Journal of Receptor, Ligand and Channel Research

\section{Publish your work in this journal}

The Journal of Receptor, Ligand and Channel Research is an international, peer reviewed, open access, online journal. The journal welcomes laboratory and clinical findings in the fields of biological receptors, ligands, channel and signal transduction research including: receptors and signaling; ligands; transporters, pores and channels; binding and activation; receptor

\section{Dovepress}

regulation; role of receptors in diseases and their treatment; molecular basis of membrane structure and functions; molecular models of membranes. The manuscript management system is completely online and includes a very quick and fair peer-review system. Visit http://www.dovepress.com/ testimonials.php to read real quotes from published authors. 